ISSN 2522-3054

December 2020, Vol. 4, $\mathrm{N}^{\circ} 1$

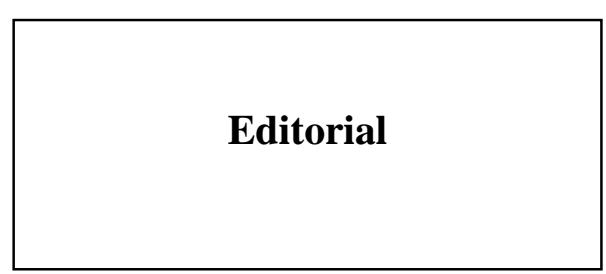

\title{
El desafío del Covid-19 en el Mundo y en el Perú
}

\author{
J. Fernando Larios-Meoño*1 \\ Universidad San Ignacio de Loyola, Lima, Perú \\ Benoit Mougenot \\ Universidad San Ignacio de Loyola, Lima, Perú
}

Con más de 60 millones de casos y más de 1 millón de fallecidos, el impacto de la pandemia del COVID-19 en el 2020 ha sido profundo, en particular a nivel de la economía mundial (Larios-Meoño, 2020). Si la magnitud de esta crisis y su naturaleza es difícilmente comparable con las anteriores, las expectativas presentan bastante incertidumbre para el próximo año, a pesar de la llegada de una vacuna en los próximos meses. El caso del Perú es particularmente interesante, debido a la aplicación temprana de mediciones de confinamiento y de distanciamiento social importantes para un país de ingreso medio, el país ha conocido una difusión masiva del virus, marcando la falta de infraestructuras y las debilidades profundas del sistema sanitario, extendiéndose finalmente a nivel económico y político. Sin embargo, a pesar de este contexto difícil ciertas actividades con el apoyo de las tecnologías de comunicación han podido desarrollarse, específicamente a nivel académico.

\footnotetext{
$1 *$ E-mail

flarios@usil.edu.pe
} 
Este número especial del Journal of Economics Finance \& International Business, tomando en cuenta el contexto especifico actual, presenta contenidos de muy alto impacto.

En primer lugar, el articulo original de Jorge Torres (2020) plantea los principales retos de recuperación post-Covid para un sector de la economía peruana clave, el sector turístico.

A continuación, los otros documentos presentados en este número se integran dentro de un ciclo de conferencias desarrollado este año en el marco de webinars a nivel de las carreras de Economía, Economía y Finanzas, Economía y Negocios Internacionales de la Universidad San Ignacio de Loyola como resúmenes de conferencia.

Alfredo Dammert (2020) se concentra sobre el sector de los minerales y sus principales retos para el próximo año.

Alvaro Orozco (2020) presenta el rol importante de fomentar Planes de Competitividad, específicamente en el marco de un desarrollo regional.

José-Luis Pereyra (2020) integra el concepto clave de sostenibilidad financiera frente a la situación post-Covid.

Finalmente, José Luis Almerco (2020). La proyección de las exportaciones en la nueva década, en un contexto de Covid 19

Ambos documentos coinciden sobre la presencia de fundamentos macroeconómicos importantes de la economía peruana y necesaria para enfrentar esta situación inédita del Covid-19.

\section{Referencias}

Almerco, J. L. (2020). La proyección de las exportaciones en la nueva década, en un contexto de Covid19. Journal of Economics Finance \& International Business. 4(1).

Dammert, A. (2020). La importancia del sector minero para el Perú. Journal of Economics Finance \& International Business. 4(1).

Larios-Meoño, J. F. (2020). El impacto del coronavirus: diez consecuencias en la economía peruana y mundial. Blog Facultad de Ciencias Empresariales. Universidad San Ignacio de Loyola. https://facultades.usil.edu.pe/ciencias-empresariales/el-impactodel-coronavirus-diez-consecuencias-en-la-economia-peruana-y-mundial/

Orozco, A. (2020). Planes de Competitividad Regional y Desarrollo. Journal of Economics Finance \& International Business. 4(1).

Pereyra, J. L. (2020). Sostenibilidad fiscal luego del Covid-19. Journal of Economics Finance \& International Business. 4(1).

Torres, J. (2020). Recuperacion post-covid: caso de turismo peruano. Journal of Economics Finance \& International Business. 4(1). 